\title{
PEMBINAAN PERACIK JAMU DI KECAMATAN KEDUNGWUNI KABUPATEN PEKALONGAN
}

\author{
Wirasti, Wulan Agustin Ningrum \\ Universitas Muhammadiyah Pekajangan Pekalongan \\ Jl.Raya Ambokembang No 8 Kedungwuni Pekalongan \\ e-mail: wirasti.kharis@gmail.com
}

\begin{abstract}
ABSTRAK
Peran pengobatan tradisional termasuk peracik obat tradisional/jamu mempunyai peranan yang cukup penting dalam pemerataan pelayanan kesehatan untuk mewujudkan derajat kesehatan masyarakat yang optimal. Ramuan yang digunakan oleh peracik obat tradisional/jamu hampir keseluruhannya terdiri lebih dari satu jenis tanaman obat.Tujuan pengabdian masyrakat ini adalah menambah pengetahuan peracik obat tradisional/jamu dalam hal aturan pemerintah tentang obat tradisional/jamu dan meningkatkan kualitas produksi peracik obat tradisional/peracik jamu.Metode pelaksanaan pengabdian masyarakat ini adalah terlebih dahulu pengumpulan data peserta, selanjutnya dilakukan pretes pada hari pelaksanaan, penyuluhan menggunakan metode ceramah dan praktek cara pembuatan obat yang baik dan sesuai aturan pemerintah. Hasil dari kegiatan ini adalah meningkatnya pengetahuan peracik jamu sebesar $400 \%$ dari nilai yang baik, Nilai cukup menurun $20 \%$ dari sebelum dilakukan kegiatan, untuk nilai kurang menjadi $0 \%$ artinya setelah dilakukan kegiatan ini jumlah peserta paracik jamu semua sudah mempunyai pengetahuan yang meningkat.Diharapkan Peracik jamu mempunyai ketrampilan yang meningkat.

Kata kunci: Peracik, jamu, ceramah, trampil
\end{abstract}

\begin{abstract}
The role of traditional medicine including compounding traditional medicine / herbal medicine has an important role in the distribution of health services to realize an optimal degree of public health. The ingredients used by traditional medicine mixers / herbal medicine almost entirely consist of more than one type of medicinal plants. The aim of this community service is to increase the knowledge of traditional medicine mixers / herbs in terms of government regulations on traditional medicines / herbs and improve the quality of production of traditional medicine mixers / herbal mixers. .The method of implementing community service is firstly collecting participant data, then pre-test on the day of implementation, counseling using lecture methods and practices for how to make medicines that are good and in accordance with government regulations. The result of this activity is an increase in the knowledge of herbal medicine mixers by $400 \%$ of good grades, the value is quite decreased by $20 \%$ from before the activity was carried out, for the value of less to $0 \%$, meaning that after this activity the number of participants of the medicinal paracik all have increased knowledge. Compounding herbal medicine has increased skills.
\end{abstract}

Keywords: Mixers, herbs, lectures, skilled 


\section{PENDAHULUAN}

Berkembangnya pengobatan tradisional belum sepenuhnya dilakukan penataan secara menyeluruh, sehingga pelayanan pengobatan tradisional masih apa adanya dan belum sepenuhnya mendapat pembinaan, serta masih diragukan bila ditinjau dari segi hygienis. Seyogianya dilakukan penataan yang menyeluruh dan bertahap agar pelayanan pengobatan tradisional aman digunakan, bermutu, bermanfaat, dan dapat dipertanggungjawabkan secara ilmiah dan hukum.

Peran pengobatan tradisional termasuk peracik obat tradisional/jamu mempunyai peranan yang cukup penting dalam pemerataan pelayanan kesehatan untuk mewujudkan derajat kesehatan masyarakat yang optimal. Ramuan yang digunakan oleh peracik obat tradisional/jamu hampir keseluruhannya terdiri lebih dari satu jenis tanaman obat. Sementara itu rencana pengembangan obat bahan alam di Badan POM, mengarah pada pengembangan produk yang terdiri dari atas satu jenis tanaman obat, melalui pendekatan pengembangan obat pada umumnya yang berbasis pada uji klinik dan banyak istilah penggunaan nama seperti obat bahan alam, obat asli Indonesia,[1] Obat tradisional, biofarmaka, jamu, ramuan yang semuanya menunjukkan pada satu arti yaitu tanaman berkhasiat obat baik empirik maupun ilmiah, yang telah beredar dan digunakan oleh masyarakat, baik diproduksi oleh industri (obat tradisional pabrikan) maupun dibuat sendiri dalam rumah tangga.[2]

Pengobatan tradisional oleh peracik obat tradisional/jamu tidak hanya diminati oleh sekelompok masyarakat desa atau mereka yang pendidikannya rendah tetapi juga mereka yang berpendidikan tinggi. Oleh karena itu perlu dilakukan pembinaan agar dalam pembuatan atau peracikan jamu memperhatikan kebersihan bahan baku alam, tempat, dan air yang digunakan untuk produksi atau peracikan

Hasil yang diharapkan dari kegiatan ini adalah peracik obat tradisional/jamu meningkatkan kualitas jamu produksinya atau racikannya, 
sehingga masyrakat konsumen lebih terjamin dalam mengkonsumsinya dan menjadi lebih sehat

\section{METODE PELAKSANAAN}

Metode yang digunakan untuk mencapai tujuan dalam kegiatan ini yaitu:

1. Mengundang peracik jamu

Semua Peracik jamu yang bertempat tinggal di Kecamatan Kedungwuni untuk mengikuti pembinaan pada hari dan tanggal yang telah ditentukan.

2. Pre test.

Sebagai tahap awal dilakukan pre test untuk semua peserta pembinaan peracik jamu bertujuan untuk mengetahui tingkat pengetahuan peracik jamu dalam melakukan kegiatan setiap harinya dalam menyiapkan jamu yang akan di perdagangkan.Pretes memuat apakah cara penyiapan, pembuatan, pengemasan dan penyimanan bahan baku yang dilakukan sudah benar,

3. Penyuluhan

Peracik jamu diberikan penyuluhan bertujuan untuk meningkatkan pengetahuan mengenai peraturan pemerintah tentang Produksi dan Peredaran Jamu atau obat tradisional, pengenalan bahan baku segar dan bermutu baik untuk jamu, pengolahan bahan baku obat alam. Keamanan Jamu. Hasil dari penyuluhan diharapkan peracik jamu lebih memahami cara pengelolaan bahan jamu menjadi lebih baik sehingga dapat mengurangi kerusakan, sehingga mengurangi kerugian.

4. Praktek pembuatan jamu yang benar.

Praktek cara pembuatan jamu dilakukan untuk memberikan informasi kepada peracik jamu cara membuat jamu sesuai dengan aturan yang benar. Praktek dipandu oleh bebrapa pemandu yang berkompeten di bidangnya 


\section{Melakukan Evaluasi}

Evaluasi kegiatan ini dilakukan kepada peracik jamu yang menjadi peserta.. Kemampuan Peserta peracik jamu dinilai melalui evaluasi (postes) yang dilakukan kepada 12 peserta.

\section{HASIL DAN PEMBAHASAN}

Hasil yang dicapai dalam kegiatan pengabdian masyarakat ini yaitu bertambahnya pengetahuan peracik jamu diwujudkan dengan hasil evaluasi yang lebih baik sehingga dikatakan pengetahuan meningkat. Selain itu cara pengolahan menjadi lebih baik, cara pengemasan yang meningkat lebih baik.Hasil dari evaluasi terdapat pada tabel 1.

Tabel 1. Distribusi frekuensi pengetahuan peracik obat sebelum dan sesudah dilakukan penyuluhan

\begin{tabular}{lccl}
\hline \multicolumn{1}{c}{ Pengetahuan } & Sebelum & Sesudah & \multicolumn{1}{c}{ Keterangan } \\
\hline Baik & 2 & 8 & Meningkat $400 \%$ \\
Cukup & 5 & 4 & Menurun 20\% \\
Kurang & 2 & 0 & Tidak Ada \\
Jumlah & 61 & 61 & \\
\hline
\end{tabular}

Hasil pengukuran menunjukkan terdapat peningkatan jumlah peracik jamu yang memiliki pengetahuan baik setelah diberikan pengetahun dengan metode penyuluhan dan praktek tentang pengelolaan bahan untuk jamu sebanyak 400\%. Hal ini menunjukkan bahwa metode penyuluhan dan praktek efektif digunakan untuk meningkatkan pengetahuan tentang penelolaan bahan jamu karena materi dan metode sangat mudah dipahami sehingga tidak perlu metode yang kompleks untuk menyampaikan materi ini kepada peracik jamu. Metode yang digunakan menggunakan 2 ( dua) macam dikarenakan tingkat pendidikan peracik jamu paling tinggi Sekolah Menengah Pertama. Pendapat ini sesuai dengan hasil penelitian lubis yang menyatakan bahwa ada pengaruh penyuluhan dengan metode ceramah terhadap peningkatan pengetahuan dan sikap.[3] 


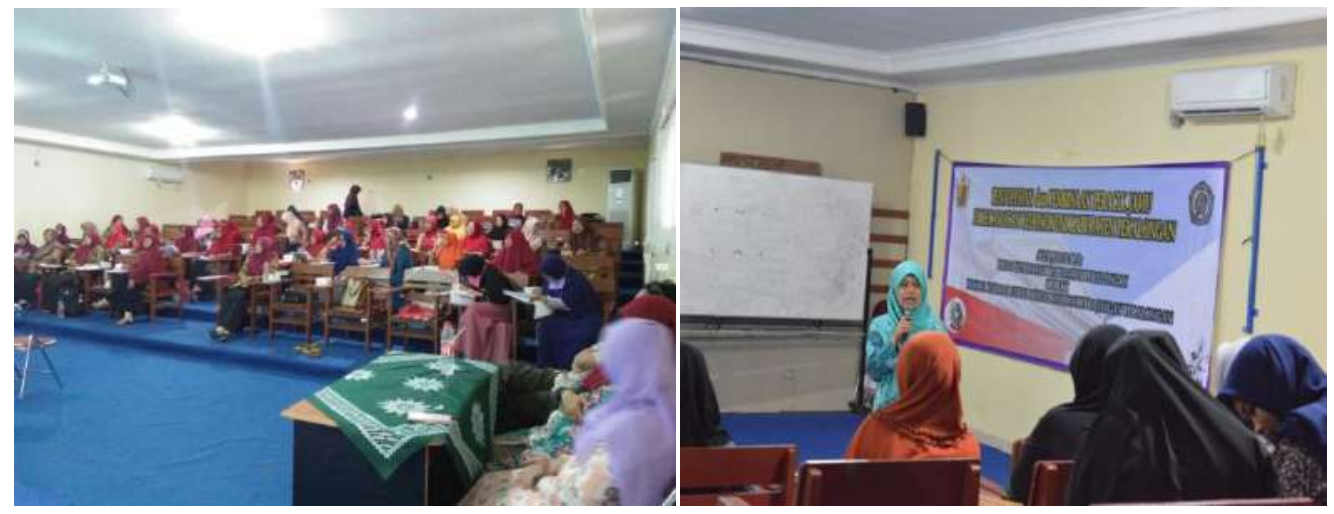

Gambar 1: Kegiatan ceramah peracik jamu di Kecamatan Kedungwuni Kabupaten Pekalongan

Kegiatan pengabdian masyarakat ini berhasil meningkatkan kemampuan pengetahuan dan ketrampilan peracik jamu tentang pengelolaan bahan obat tradisional atau jamu dengan baik. Dengan bekal pengetahuan dan tambahan ketrampilan diharapkan terbentuk pola pengelolaan, pembuatan, pengemansan dan penyimpanan jamu. Implikasinya Peracik jamu dalam memproduksi jamu yang akan dijual mempunyai kualitas yang baik. Hal ini salah satu penyumbang masyrakat dalam meningkatkan kesehatan masyarakat.

\section{SIMPULAN DAN SARAN}

\section{Simpulan}

Simpulan dari kegiatan pengabdian masyarakat ini adalah sebagai berikut:

1. Terbentuknya kelompok peracik jamu yang sudah terlatih

2. Terdapat peningkatan peracik jamu yang memiliki pengetahuan dan keterampilan sesuai dengan aturan pengelolaan jamu

\section{Saran}

Perlu adanya pengelolaan, pengetahuan dan keterampilan peracik jamu yang lebih intensif dan dilaksanakan secara berkesinambungan. 


\section{DAFTAR PUSTAKA}

1. Ningrum, Wulan Agustin, Ainun Muthoharoh, dan M. Suaeful Bahrie. "Hubungan Karakteristik dan Tingkat Pengetahuan Responden Prolanis Terhadap Pengobatan Diabetes Melitus Tipe II di Wilayah Kerja Puskesmas Wonopringgo Kabupaten Pekalongan." Urecol 11 (12 Mei 2020): 26-30.

2. Wirasti, Wirasti. "Penetapan Kadar Fenolik Total, Flavonoid Total, dan Uji Aktivitas Antioksidan Ekstrak Daun Benalu Petai (Scurrula atropurpurea Dans.) Beserta Penapisan Fitokimia." Pharmaceutical And Medicinal Science 4, no. 1 (4 September 2019).

3. Ningrum, Muthoharoh, dan Bahrie, "Hubungan Karakteristik dan Tingkat Pengetahuan Responden Prolanis Terhadap Pengobatan Diabetes Melitus Tipe II di Wilayah Kerja Puskesmas Wonopringgo Kabupaten Pekalongan." 